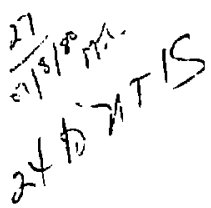

\title{
Accuracy of various alternate methods of calculating total mass flow rate for PKL instrumented pipe spool prototype tests in single- and two-phase steam-water flows
}

Werner Stein

MSTER

December 1979 


\title{
Accuracy of various alternate methods of calculating total mass flow rate for PKL instrumented pupe spool prototype tests in single- and two-phase steam-water flows
}

\author{
Werner Stein
}

Manuscript date: December 1979 
ABSTRACT

Instrumented spool pieces for installation in the piping of the German Primarkreislauf (PKL) test reactor have been designed and tested. The spools have been developed as part of a joint cooperative German, Japanese, and United States steam-binding study for the U. S. Nuclear Regulatory Comission, Division of Reactor Safety Research (NRC-RSR).

The primary objective of the spools is to provide measurements of two-phase steam-water flow parameters (pressure, temperature, velocity) from which mass flow rates can be calculated.

Each spool contains a three-beam densitometer, flow turbine, drag screen, and pressure and temperature sensors. The spools were prototype tested $^{1}$ in single- and two-phase steam-water flows and the results of the mass flow calculations were compared to known values.

The present software calculations of total mass fluw in two-phase flows requires data from two instruments only: the flow turbine and drag screen. In this report, mass flow calculations based on other instrument combinations are investigated and compared to the programmed calculations. Instrument combinations considered included: densitometer and drag screen, densitometer and flow turbine, differential pressure sensor and flow turbine, and temperature and drag screen. The effect of changes in slip ratio on mass flow calculations also was investigated.

Results of the mass flow calculations show that the primary model involving the drag screen and turbine gives the most accurate results in most cases. 
CONTENTS

Abstract . . . . . . . . . . . . . . . . . i i

Introduction . . . . . . . . . . . . . . . . . 1

Discussion . . . . . . . . . . . . . . . . . . 2

Analytical Models . . . . . . . . . . . . . . . 4

Single-Phase Superheated Steam Flow . . . . . . . . 4

Two-Phase Flow . . . . . . . . . . . . . . 6

Instrument Combinations . . . . . . . . . . 6

Validity of Flow Turbine Data . . . . . . . . . 7

Slip Flow Correlations . . . . . . . . . . 7

Density . . . . . . . . . . . . . . . 7

Flow Turbine . . . . . . . . . . . . . 7

Drag Screen - . . . . . . . . . . . 8

Slip Corrections . . . . . . . . . . 8

Results . . . . . . . • . . . . . . . . . 9

Superheated Steam Flows . . . . . . . . . . 10

Two-Phase Flows . . . . . . . . . . . . . . 12

Slip Corrections in Two-Phase Flows . . . . . . . . . 12

References. . . . . . . . . . . . . . 19 
1. Total superheated steam mass flow rate $(\mathrm{kg} / \mathrm{s})$ and percentage differences $(\%) . . . . . . . . .17$

2. Slug flow regime total mass flow rates $(\mathrm{kg} / \mathrm{s})$ and

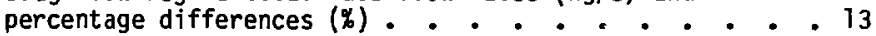

3. Annular mist flow regime total mass flow rates $(\mathrm{kg} / \mathrm{s})$

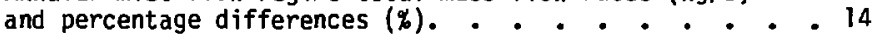

4. Froth flow regime total mass flow rates $(\mathrm{kg} / \mathrm{s})$ and percentage differences $(\%) . . .0 . . .0 .016$

5. Wave flow regime total mass flow rates $(\mathrm{kg} / \mathrm{s})$ and percentage differences $(\%) . . . . . . . . .17$ 
ACCURACY OF VARIOUS ALTERNATE METHODS OF GALCULATING TOTAL MASS

FLOW RATE FOR PKL INSTRUMENTED PIPE SPOOL PROTOTYPE TESTS IN

SINGLE- AND THO-PHASE STEAM-WATER FLOWS

INTRODUCTION

Instrumented spool pieces for installation in the piping of the German Primarkreislauf (PKL) test reactor have been designed and tested. The spools have been developed as part of a joint cooperative German, Japanese, and United States steam-binding study for the U. S. Nuclear Regulatory Commission, Division of Reactor Safety Research (NRC-RSR) under the 3-D Technical Support and Instrumentation Program.

The primary objective of the spools is to provide measurements of twophase steam-water flow parameters (pressure, temperature, velocity) from which mass flow rates can be calculated.

Four spools were constructed. Each spool contains a 3-beam densitometer, flow turbine, drag screen, and pressure and temperature sensors. Both the computer system and the software are supplied with the four spools to record data and perform calculations to determine mass flow rates and related flow-parameters. A detailed description of the hardware and software is given in Ref. 1 .

Three spools were prototype-tested in single-phase and two-phase steamwater flows. Reference 1 gives both the results and an error analysis for these prototype tests. The results indicated a very good capability of measuring single- and two-phase flows. For these tests, total two-phase mass flow rate is calculated based on measurements obtained from only the drag screen and flow turbine.

Alternate methods of calculating the total mass flow rate, in singleand two-phase flows, are possible. These methods involve using different 
instrument combinations, with certain combinations expected to give better accuracy in the various two-phase flow regimes. In this report, various alternate calculational procedures are investigated and their accuracies in determining mass flow rates are compared.

The results of the various two-phase alternate model calculations show that the primary model, which uses the drag screen and flow turbine, is definitely the best model over the range of flow conditions and flow regimes encountered in the PKL prototype tests.

In certain specific flow conditions one of the many models will give better accuracy. After review of all the alternate models, however, no modifications to the software calculational procedures are recommended.

\section{DISCUSSION}

In two-phase flows of steam and water, various flow regimes, which are dependent on the relative flow rates of steam and water, are possible. For PKL prototype tests, steam and water flow rates were adjusted to result in the following flow regimes: slug, annular mist, wave, and froth. In each of the flow regimes, the velocity of the steam may be different from the velocity of the water, with the ratio of steam velocity to water velocity defined as the slip ratio.

The drag screen and flow turbine are calibrated in single-phase flow (slip ratio equal to one). Operation of these instruments in two-phase flows with a slip ratio greater than one will result in a measured output that differs from the output predicted from single-phase calibrations ${ }^{2}$. An additional consideration for slip flows is the effect on mass flow calculations because of changes in slip ratio at the flow turbine that are due to disturbances caused by the upstream drag screen. 
The primary method of calculating total mass flow involves the measurement of momentum flux by the drag screen and the measurement of velocity by the flow turbine. Dividing the momentum flux by the velocity and multiplying by the cross-sectional area of the spool gives the total mass flow rate.

Alternate means of calculating total mass flow rate in two-phase flows that are investigated in this report involve the following instrument combinations:

- Densitometer and drag screen

- Densitometer and flow turbine

- Densitometer and differential pressure sensor across the drag screen

- Flow turbine and differential pressure sensor across the drag screen

The differential pressure sensor in two of the above models is used to measure the pressure drop across the drag screen, which is then related to moxentum flux. Normally the momentum flux is determined from a calibration of drag force on the screen versus momentum flux. The force is obtained from three transducers holding the drag screen in place.

Alternate methods of calculating single-phase superheated steam mass flow rates were al so investigated. Two methods are presently incorporated in the software. The instrunent combinations involved in these two methods are:

- Flow turbine and pressure and temperature sensors

- Densitometer and drag screen

The instrument combinations for al ternate calculations of superheated steam mass flow rates are:

- Drag screen and pressure and temperature sensors

- Drag screen and flow turbine

- Differential pressure probe and temperature and pressure sensors

- Densitometer and flow turbine 


\section{ANALYTICAL MODELS}

The analytical modeis for single-phase and two-phase steam-water mass flow rate calculations are presented below.

SINGLE-PHASE SUPERHEATED STEAM FLOW

The mass flow rate in single-phase superheated steam flow (MS) is calculated using the following equation:

$$
\text { MS }=A \times R H O S \times V T
$$

where

$$
\begin{aligned}
\text { RHOS = } & \text { Steam density obtained from steam tables based } \\
& \text { upon measured temperature and pressure. } \\
V T= & \text { Velocity obtained from the flow turbine based } \\
& \text { upon an air calibration. } \\
A= & \text { Cross-sectional area of the spool. }
\end{aligned}
$$

The software has also been programed to perform an additional calculation for total mass flow rate (MF) as given by equation (2).

$$
M S X=A \times \sqrt{D B(3) \times D T T}
$$

where

$$
\begin{aligned}
\mathrm{OB}(3)= & \text { Steam density measured by the most accurate of } \\
& \text { the three densitometer beams in the steam } \\
& \text { density range. }
\end{aligned}
$$


DTT = Momentum flux as sensed by the three drag screen transducers.

Four alternate methods, using four different instrument combinations, were investigated, and the relationship for the steam mass flow rate (MS:) of each combination is given by equations (3) through (6).

- Drag screen and pressure and temperature sensors:

$$
\text { MS1 }=A \times \sqrt{\text { RHOS } \times \text { DTT }}
$$

- Drag screen and flow turbine:

$$
\text { MS2 }=\frac{A \times \text { DTT }}{V T}
$$

- Differential pressure sensor and pressure and temperature sensors:

$$
\text { MS3 }=A \times \sqrt{\text { RHOS } \times \text { POTT }}
$$

where

$$
\begin{aligned}
\text { PDTT }= & \text { momentum flux obtained from a pressure } \\
& \text { drop calibration across the drag screen. }
\end{aligned}
$$

- Densitometer and flow turbine:

$$
M S 4=A \times O B(3) \times V T
$$

In addition to the values from the models above, average values of mass flow rates that were obtained by adding the results of various models were also investigated. 
Instrument Combinations

The primary model for calculating total mass flow rate (MF) is given by:

$$
M F=\frac{A \times D T T}{V T}
$$

Four alternate methods using four different instrumentation combinations were investigated. The relationship for total mass flow rate is given by equations (8) through (11).

- Densitometer and drag screen:

MFA $=A \times \sqrt{\text { RHOF } \times \text { DTT }}$

where

RHOF = average pipe cross sectional dencity determined from the densitometer beam measurements.

- Densitometer and flow turbine:

$$
\text { MFB }=A \times \text { RHOF } \times \text { VT }
$$

- Densitometer and differential pressure sensor:

$$
\text { MFC }=A \times \sqrt{\text { RHOF } \times \text { PDTT }}
$$

- Flow turbine and differential pressure sensor:

$$
\text { MFD }=\frac{A \times P D T T}{V T}
$$


Validity of Flow Turbine Data

Checks on the validity of the flow turbine data are made in the software coding. If the turbine data is rejected, the total mass fiow raie calculations default to the calculation given in equation (8).

\section{SLIP FLOW CORRELATIONS}

\section{Density}

The av' age cross-sectional density, RHOF, is relaced to individual phase densities and the void fraction by:

$$
\text { RHOF }=\alpha p_{s}+(1 \cdots \alpha) p_{w}
$$

where

$$
\begin{aligned}
& \alpha=\text { yoid fraction } \\
& \rho_{S}=\text { steam density } \\
& \rho_{W}=\text { water density }
\end{aligned}
$$

\section{Flow Turbine}

The flow turbine is calibrated in single-phase flow to obtain a calibration table of rotor turning rate versus average fluid velocity. In two-phase flow the velocity measured by the turbine $\left(V_{t}\right)$ is assumed equal to the quality-weighted phase velocities. ${ }^{3}$

$$
v_{t}=x V_{s}+(1-x) V_{w}
$$

where

$$
\begin{aligned}
X & =\text { flow quality } \\
v_{S} & =\text { steam velocity } \\
v_{w} & =\text { water velocity }
\end{aligned}
$$


Equation (13) can be rewricten as:

$$
V T=\frac{\alpha \rho_{s} V_{s}^{2}+(1-\alpha) \rho_{w} V_{s}^{2}}{\alpha \rho_{s} V_{s}+(1-\alpha) \rho_{w} V_{w}}
$$

\section{Drag Screen}

The measured drag force from the drag screen is related to mumentum flux of single-phase flow by a DTT calibration table. The momentum flux in two-phase flows is given by:

$$
\mathrm{DTT}=\alpha \rho_{s} v_{s}^{2}+(1-\alpha) \rho_{w} v_{w}^{2}
$$

\section{Slip Corrections}

The mass $f 7 u x\left(\frac{m}{A}\right)$ is given by:

$$
\frac{h}{A}=\alpha \rho_{S} v_{S}+(l-\alpha) p_{w} v_{w}
$$

and the slip ratio (S) is given by:

$$
S=\frac{v_{s}}{V_{w}}=\left(\frac{1-\alpha}{\alpha}\right) \frac{\rho_{w}}{\rho_{S}}\left(\frac{x}{1-x}\right)
$$

:

Using equations 16 and 17 , equation 14 can be written ${ }^{2}$ as:

$$
v T=\left(\frac{n}{\bar{A}}\right)\left(\frac{(1-x) S_{T}}{p_{W}}+\frac{x}{\rho_{S}}\right) \times\left(+\frac{1-X}{S_{T}}\right)
$$

where

$$
S_{T}=s \text { lip at the turbine }
$$


as: Using equations (14), (16), and (18), equation (15) can be rewritten

$$
\text { DTT }=\left(\frac{A}{A}\right)^{2}\left(\frac{(1-x)}{P_{W}} S_{D S}+\frac{X}{\rho_{S}}\right)\left(x+\frac{1-X}{S_{D S}}\right)
$$

where

$$
S_{D S}=s l i p \text { at the drag screen }
$$

Substituting equations (19) and (18) into equation (7) gives:

where

$$
\mathrm{m}=\operatorname{MF}\left[\left(\begin{array}{l}
\left(\frac{(1-x) S}{\rho_{W}}+\frac{x}{\rho_{S}}\right)\left(x+\frac{1-x}{S_{T}}\right. \\
\left.\frac{(1-\bar{x}) S_{D S}}{\rho_{W}}+\frac{I-x}{\rho_{S}}\right)\left(x+\frac{1}{s_{D S}}\right)
\end{array}\right]\right.
$$

$$
m=\text { slip-corrected mass flow rate }
$$

Equation (20) reduces to equation (7) for cases of unity slip or for equal values of slip at the turbine and drag screen. The slip ratio at the turbine downstream from the drag screen may be different from the slip at the drag screen due to flow disturbance caused by the drag screen.

\section{RESULTS}

The spools that were prototype-tested included the following:

- 80.8-mm diameter horizontal spool (designated spool no. 1).

- 113-mm diamete - horizontal spool (designated spool no. $\because \vdots$.

- 80.8-mm diameter vertical spool (designated spool no. 4). 
The fourth spool (spool no. 2) was not tested since it is essentially identical to spool no. 1 .

Prototype testing involves testing the spools with the flow in the forward direction and also with the flow in the reverse direction. Changing the flow direction is accomplished by physically turning the spool around in the piping system. Various tests are repeated several times, on different days, and at essentially identical flow conditions to determine repeatability. Spool nos. 1 and 3 were tested under horizontal flow conditions, and spool no. 4 was tested under vertical flow conditions.

Each of the spools was tested in single-phase water flow, single-phase superheated steam (approximately 10 to $40^{\circ} \mathrm{F}$ superheat), and two-phase water and steam flows. For two-phase horizontal flow, the flow regimes during testing included slug flow, stratified wavy flow, and annular mist flow. For two-phase vertical flow, the flow regimes during testing were slug flow, froth flow, and annular mist flow. The two-phase flow testing was done at saturation conditions and was conducted at three different fluid pressures, i.e., 620, 414, and $207 \mathrm{kPa}(90,60$, and $30 \mathrm{psia}$, respectively).

\section{SUPERHEATED STEAM FLOW}

Applying equations (1) through (6) to data obtained from the PKL prototype superheated steam flow tests ${ }^{1}$ gives the results shown in Table 1. Table 1 lists the average mass flow rate and the percentage difference relative to the known mass flow rate for each of the six models given by equations (1) through (6).

The table also shows the mass flow rate (MA) (and percentage difference) given by the average of the results from equations (1) and (2):

$$
M A=\frac{M S+M S X}{2}
$$


TABLE 1. Total superheated steam mass flow rate $(\mathrm{kg} / \mathrm{s})$ and percentage differences $(\%)$.

\begin{tabular}{|c|c|c|c|c|c|c|c|c|c|c|c|c|c|c|c|c|}
\hline $\begin{array}{l}\text { Test } \\
\text { no. }\end{array}$ & $w^{b}$ & HS & $x$ & $M S X$ & $\%$ & MSl & $\%$ & $\mathrm{MS} 2$ & $\%$ & MS3 & $\%$ & MSA & $\%$ & $M A$ & $\%$ & $\begin{array}{l}\text { Flow } \\
\text { dir. }\end{array}$ \\
\hline
\end{tabular}

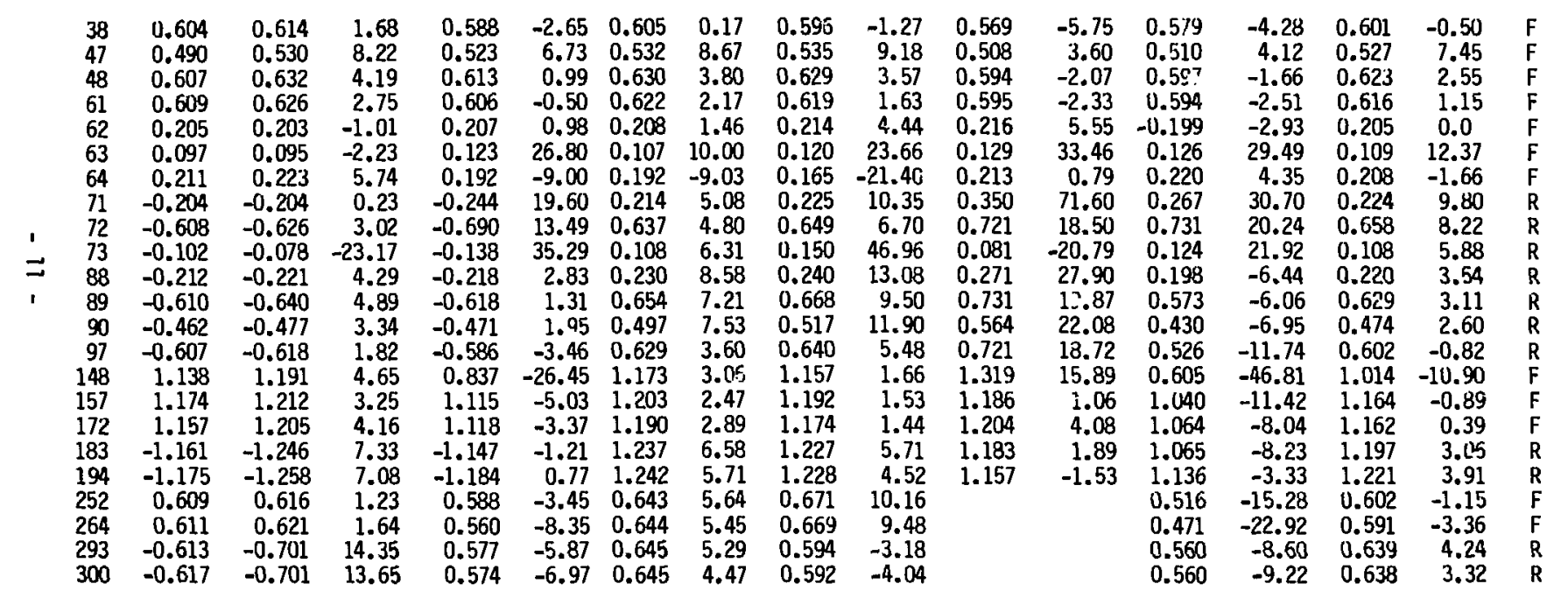

\footnotetext{
a represents prototype test number as given in Ref. 1. b"W" represents known values of mass flow rate.
} 
Analyzing tine results of Table 1 shows that the primary model given by equation (1) appears to give the best results for forward flows and the model given by equation (21) appears to give the best results for reverse flows.

The present software prints out the results of calculations based on equations (1) and (2). To obtain the results of equation (21), an average of the results of equations (1) and (2) must be taken.

TWO-PLIASE FLOWS

The results from applying equations (7) through (11) to the PKL prototype test datal give the total mass flow rate data in Tables $2,3,4$, and 5 for the slug, annular mist, froth, and wave flow regimes. Negative mass flow rate values indicate flows in the reverse direction.

For the slug flow regime data of Table 2, the primary model gives better results than all the other models for reverse flows. For forward flows, the model (MFA) given by equation (8) appears to be better for spool number 3 .

For the annular mist flow regime data of Table 3, the primary model, shown by equation (8), appears to be best.

For the froth and wave flow regime data given in Tables 4 and 5 , the primary model equation ( 8 ) gives the best results.

\section{SLIP CORRECTIONS IN TWO-PHASE FLOWS}

The effect of slip on mass flow calculations is given by equation (20). From this relation one can see that if the slip ratio at the turbine is smaller than at the drag screen, the corrected mass flow rate will be increased, as well as the converse. 
TABLE 2. Slug flow regime total mass flow rates $(\mathrm{kg} / \mathrm{s})$ and percentage differences $(\%)$.

\begin{tabular}{|c|c|c|c|c|c|c|c|c|c|c|c|c|c|}
\hline $\begin{array}{l}\text { Test } \\
\text { no. }\end{array}$ & $\begin{array}{l}\text { Flow } \\
\text { dir. }\end{array}$ & $\begin{array}{c}\text { Spool } \\
\text { no. }\end{array}$ & $W$ & MF & $\%$ & MFA & $\%$ & MFB & $\%$ & MFC & $\%$ & MFO & $\%$ \\
\hline $\begin{array}{r}36 \\
41 \\
56 \\
57 \\
59 \\
75 \\
79 \\
84 \\
94 \\
99 \\
146 \\
155 \\
161 \\
164 \\
170 \\
178 \\
182 \\
190 \\
192 \\
251 \\
260 \\
286 \\
289\end{array}$ & $\begin{array}{l}F \\
F \\
F \\
F \\
F \\
R \\
R \\
R \\
R \\
R \\
F \\
F \\
F \\
F \\
F \\
R \\
R \\
R \\
R \\
F \\
F \\
R \\
R\end{array}$ & $\begin{array}{l}1 \\
1 \\
1 \\
1 \\
1 \\
1 \\
1 \\
1 \\
1 \\
1 \\
3 \\
3 \\
3 \\
3 \\
3 \\
3 \\
3 \\
3 \\
3 \\
4 \\
4 \\
4 \\
4\end{array}$ & $\begin{array}{r}4.351 \\
4.335 \\
3.156 \\
4.376 \\
3.020 \\
-4.393 \\
-3.077 \\
-3.086 \\
-7.340 \\
-4.438 \\
8.470 \\
5.758 \\
8.398 \\
5.929 \\
8.414 \\
-8.543 \\
-5.849 \\
-5.858 \\
-8.422 \\
7.384 \\
1.458 \\
-7.350 \\
-1.509\end{array}$ & $\begin{array}{r}3.939 \\
3.656 \\
2.651 \\
3.997 \\
2.891 \\
-4.835 \\
-3.860 \\
-2.937 \\
-4.548 \\
-4.143 \\
6.205 \\
4.287 \\
6.232 \\
4.592 \\
6.267 \\
-7.791 \\
-6.001 \\
-5.283 \\
-7.436 \\
5.950 \\
1.655 \\
-6.810 \\
-2.057\end{array}$ & $\begin{array}{r}-9.5 \\
-15.7 \\
-16.0 \\
-8.7 \\
-4.3 \\
10.1 \\
25.4 \\
-4.8 \\
4.8 \\
-6.7 \\
-26.7 \\
-25.5 \\
-25.8 \\
-22.6 \\
-25.5 \\
-8.8 \\
2.6 \\
-9.8 \\
-11.7 \\
-19.4 \\
13.5 \\
-7.4 \\
36.3\end{array}$ & $\begin{array}{l}4.467 \\
4.324 \\
3.611 \\
4.601 \\
3.936 \\
4.994 \\
4.241 \\
4.115 \\
4.637 \\
4.451 \\
9.049 \\
7.318 \\
9.051 \\
6.758 \\
9.139 \\
9.507 \\
7.271 \\
6.777 \\
9.156 \\
5.958 \\
1.640 \\
6.790 \\
2.041\end{array}$ & $\begin{array}{c}2.7 \\
-0.26 \\
14.4 \\
5.1 \\
30.3 \\
13.7 \\
37.8 \\
40.1 \\
6.8 \\
0.29 \\
6.8 \\
27.1 \\
7.8 \\
14.0 \\
8.6 \\
11.3 \\
24.3 \\
15.7 \\
8.7 \\
-19.3 \\
12.5 \\
-7.6 \\
35.3\end{array}$ & $\begin{array}{r}4.898 \\
5.093 \\
4.916 \\
5.175 \\
5.370 \\
4.788 \\
4.665 \\
6.057 \\
4.727 \\
4.788 \\
13.190 \\
12.497 \\
13.150 \\
9.937 \\
13.347 \\
11.613 \\
8.820 \\
8.695 \\
11.290 \\
3.640 \\
0.602 \\
4.732 \\
1.612\end{array}$ & $\begin{array}{r}12.6 \\
17.5 \\
55.8 \\
18.3 \\
77.8 \\
9.0 \\
51.6 \\
96.3 \\
8.9 \\
7.9 \\
55.7 \\
117.0 \\
56.6 \\
67.6 \\
58.6 \\
35.9 \\
50.8 \\
48.4 \\
34.1 \\
-50.7 \\
-58.7 \\
-35.6 \\
6.9\end{array}$ & $\begin{array}{r}5.435 \\
5.347 \\
4.672 \\
5.866 \\
5.063 \\
7.465 \\
6.037 \\
6.144 \\
6.895 \\
6.968 \\
12.016 \\
9.308 \\
12.105 \\
9.145 \\
12.179 \\
14.201 \\
9.105 \\
10.465 \\
13.945\end{array}$ & $\begin{array}{l}24.9 \\
23.3 \\
48.0 \\
34.1 \\
67.7 \\
70.0 \\
96.2 \\
99.1 \\
58.9 \\
57.0 \\
41.9 \\
61.7 \\
44.1 \\
54.2 \\
44.8 \\
66.2 \\
55.7 \\
78.7 \\
65.6\end{array}$ & $\begin{array}{r}6.031 \\
5.613 \\
4.440 \\
6.650 \\
4.774 \\
11.641 \\
7.812 \\
6.232 \\
10.060 \\
10.141 \\
10.947 \\
6.932 \\
11.143 \\
8.416 \\
11.113 \\
17.364 \\
9.399 \\
12.597 \\
17.225\end{array}$ & $\begin{array}{r}38.6 \\
29.5 \\
40.7 \\
52.0 \\
58.1 \\
165.0 \\
153.9 \\
101.9 \\
131.7 \\
128.5 \\
29.2 \\
20.4 \\
32.7 \\
41.9 \\
32.1 \\
103.3 \\
60.7 \\
115.0 \\
104.5\end{array}$ \\
\hline
\end{tabular}


TABLE 3. Annular mist flow regime total mass flow rates $(\mathrm{kg} / \mathrm{s})$ and percentage differences $(\%)$.

\begin{tabular}{|c|c|c|c|c|c|c|c|c|c|c|c|c|c|}
\hline $\begin{array}{l}\text { Test } \\
\text { no. }\end{array}$ & $\begin{array}{l}\text { Flow } \\
\text { dir. }\end{array}$ & $\begin{array}{c}\text { Spool } \\
\text { no. }\end{array}$ & $W$ & MF & $\%$ & MFA & $\%$ & MFB & $\%$ & $M F C$ & $\%$ & MFU & $\%$ \\
\hline $\begin{array}{l}37 \\
42 \\
43 \\
45 \\
46 \\
54 \\
55 \\
58 \\
69 \\
70 \\
80 \\
81 \\
82 \\
83 \\
91 \\
92 \\
93 \\
98 \\
147 \\
152 \\
153 \\
154 \\
158 \\
159 \\
162 \\
163 \\
171\end{array}$ & $\begin{array}{l}F \\
F \\
F \\
F \\
F \\
F \\
F \\
F \\
R \\
R \\
R \\
R \\
R \\
R \\
R \\
R \\
R \\
R \\
F \\
F \\
F \\
F \\
F \\
F \\
F \\
F \\
F\end{array}$ & $\begin{array}{l}1 \\
1 \\
1 \\
1 \\
1 \\
1 \\
1 \\
1 \\
1 \\
1 \\
1 \\
1 \\
1 \\
1 \\
1 \\
1 \\
1 \\
1 \\
3 \\
3 \\
3 \\
3 \\
3 \\
3 \\
3 \\
3 \\
3\end{array}$ & $\begin{array}{r}0.804 \\
0.811 \\
1.025 \\
0.554 \\
0.932 \\
0.382 \\
0.655 \\
0.795 \\
-0.752 \\
-1.044 \\
-0.542 \\
-0.878 \\
-0.667 \\
-0.391 \\
-0.799 \\
-1.042 \\
-0.763 \\
-0.761 \\
1.438 \\
1.095 \\
1.111 \\
1.765 \\
2.049 \\
1.426 \\
1.298 \\
0.771 \\
1.455\end{array}$ & $\begin{array}{r}0.756 \\
0.785 \\
1.363 \\
0.632 \\
0.916 \\
0.494 \\
0.684 \\
0.769 \\
-0.800 \\
-1.590 \\
-0.731 \\
-0.930 \\
-0.818 \\
-0.687 \\
-0.882 \\
-1.523 \\
-0.836 \\
-0.829 \\
1.190 \\
1.194 \\
1.208 \\
1.439 \\
1.909 \\
1.185 \\
1.110 \\
0.715 \\
1.201\end{array}$ & $\begin{array}{r}-6.0 \\
-3.2 \\
33.0 \\
14.1 \\
-1.7 \\
29.3 \\
4.4 \\
-3.2 \\
6.4 \\
52.3 \\
34.3 \\
5.9 \\
22.6 \\
75.7 \\
10.3 \\
46.2 \\
9.6 \\
9.0 \\
-17.2 \\
9.0 \\
8.7 \\
-18.5 \\
-6.8 \\
-16.9 \\
-14.5 \\
-7.3 \\
-17.5\end{array}$ & $\begin{array}{l}1.074 \\
1.093 \\
2.075 \\
1.080 \\
1.154 \\
0.906 \\
1.190 \\
1.096 \\
1.013 \\
1.587 \\
0.873 \\
1.087 \\
1.152 \\
0.877 \\
1.108 \\
1.521 \\
1.062 \\
1.064 \\
1.187 \\
2.411 \\
2.470 \\
1.969 \\
2.904 \\
1.768 \\
1.859 \\
1.646 \\
1.768\end{array}$ & $\begin{array}{r}33.6 \\
34.8 \\
102.4 \\
95.0 \\
23.9 \\
137.1 \\
81.7 \\
37.8 \\
34.7 \\
52.0 \\
61.0 \\
23.8 \\
72.8 \\
124.2 \\
38.7 \\
46.0 \\
39.2 \\
39.8 \\
-17.5 \\
120.2 \\
122.3 \\
11.5 \\
41.7 \\
49.2 \\
43.3 \\
113.5 \\
21.5\end{array}$ & $\begin{array}{l}1.526 \\
1.522 \\
3.159 \\
1.850 \\
1.455 \\
1.663 \\
2.072 \\
1.561 \\
1.282 \\
1.408 \\
1.045 \\
1.272 \\
1.625 \\
1.171 \\
1.393 \\
1.277 \\
1.351 \\
1.364 \\
1.183 \\
4.875 \\
5.056 \\
2.693 \\
4.416 \\
2.640 \\
3.114 \\
3.795 \\
2.604\end{array}$ & $\begin{array}{r}89.8 \\
87.7 \\
208.2 \\
233.9 \\
56.1 \\
335.3 \\
216.3 \\
96.3 \\
70.5 \\
34.8 \\
92.8 \\
44.9 \\
143.6 \\
199.5 \\
74.3 \\
22.6 \\
77.1 \\
79.3 \\
-17.7 \\
345.2 \\
355.0 \\
52.6 \\
115.5 \\
85.1 \\
139.9 \\
392.3 \\
79.0\end{array}$ & $\begin{array}{l}1.088 \\
1.101 \\
2.201 \\
1.198 \\
1.165 \\
0.957 \\
1.212 \\
1.123 \\
1.243 \\
2.225 \\
1.246 \\
1.311 \\
1.395 \\
1.077 \\
1.355 \\
2.122 \\
1.282 \\
1.309 \\
1.227 \\
2.684 \\
2.733 \\
2.053 \\
2.987 \\
1.844 \\
1.919 \\
1.902 \\
1.841\end{array}$ & $\begin{array}{r}35.4 \\
35.8 \\
114.7 \\
116.2 \\
25.0 \\
150.5 \\
85.0 \\
41.3 \\
65.3 \\
113.2 \\
129.8 \\
49.3 \\
109.1 \\
175.3 \\
69.6 \\
103.6 \\
68.0 \\
72.0 \\
-14.7 \\
145.1 \\
146.0 \\
16.3 \\
45.8 \\
29.3 \\
47.9 \\
146.7 \\
26.5\end{array}$ & $\begin{array}{l}0.776 \\
0.796 \\
1.533 \\
0.776 \\
0.933 \\
0.551 \\
0.709 \\
0.808 \\
1.205 \\
3.519 \\
1.485 \\
1.352 \\
1.197 \\
0.990 \\
1.318 \\
3.525 \\
1.216 \\
1.256 \\
1.213 \\
1.478 \\
1.478 \\
1.566 \\
2.020 \\
1.289 \\
1.183 \\
0.953 \\
1.301\end{array}$ & $\begin{array}{r}-3.5 \\
-1.8 \\
49.5 \\
40.0 \\
0.1 \\
44.2 \\
8.2 \\
1.6 \\
60.2 \\
237.0 \\
174.0 \\
54.0 \\
79.5 \\
153.1 \\
65.0 \\
238.3 \\
59.3 \\
65.1 \\
-11.5 \\
35.0 \\
33.0 \\
-11.3 \\
-1.4 \\
-9.6 \\
-8.9 \\
23.6 \\
-10.6\end{array}$ \\
\hline
\end{tabular}


TABLE 3. Annular mist flow regime mass flow rates $(\mathrm{kg} / \mathrm{s})$ and percentage differences (\%) (Contd).

\begin{tabular}{|c|c|c|c|c|c|c|c|c|c|c|c|c|c|}
\hline $\begin{array}{l}\text { Test } \\
\text { no. }\end{array}$ & $\begin{array}{l}\text { Flow } \\
\text { dir. }\end{array}$ & $\begin{array}{c}\text { Spool } \\
\text { no. }\end{array}$ & $W$ & MF & $\%$ & MFA & $q$ & MFB & $\%$ & MFC & $\%$ & MFD & $\%$ \\
\hline $\begin{array}{l}175 \\
176 \\
180 \\
181 \\
189 \\
191 \\
193 \\
245 \\
246 \\
249 \\
250 \\
262 \\
263 \\
282 \\
283 \\
287 \\
288 \\
291 \\
292\end{array}$ & $\begin{array}{l}R \\
R \\
R \\
R \\
R \\
R \\
R \\
F \\
F \\
F \\
F \\
F \\
F \\
R \\
R \\
R \\
R \\
R \\
R\end{array}$ & $\begin{array}{l}3 \\
3 \\
3 \\
3 \\
3 \\
3 \\
3 \\
4 \\
4 \\
4 \\
4 \\
4 \\
4 \\
4 \\
4 \\
4 \\
4 \\
4 \\
4\end{array}$ & $\begin{array}{r}-1.443 \\
-2.020 \\
-1.709 \\
-1.105 \\
-0.779 \\
-1.312 \\
-1.471 \\
0.653 \\
0.843 \\
1.016 \\
0.747 \\
1.404 \\
0.890 \\
-0.660 \\
-0.867 \\
-1.039 \\
-0.755 \\
-1.413 \\
-0.867\end{array}$ & $\begin{array}{r}-1.360 \\
-2.625 \\
-1.580 \\
-1.792 \\
-1.413 \\
-1.311 \\
-1.361 \\
0.644 \\
0.960 \\
1.086 \\
0.723 \\
1.467 \\
0.840 \\
-0.770 \\
-1.261 \\
-1.310 \\
-0.706 \\
-1.897 \\
-0.802\end{array}$ & $\begin{array}{r}-5.8 \\
29.9 \\
-7.6 \\
62.2 \\
81.4 \\
-0.1 \\
-7.5 \\
-1.4 \\
13.9 \\
6.9 \\
-3.2 \\
4.5 \\
-5.7 \\
16.7 \\
45.5 \\
26.1 \\
-6.4 \\
34.3 \\
-7.5\end{array}$ & $\begin{array}{l}1.725 \\
3.050 \\
1.909 \\
2.058 \\
1.675 \\
1.900 \\
1.811 \\
1.257 \\
1.473 \\
1.657 \\
1.066 \\
2.039 \\
1.124 \\
1.054 \\
1.456 \\
1.511 \\
0.972 \\
2.048 \\
0.998\end{array}$ & $\begin{array}{r}19.5 \\
51.0 \\
11.7 \\
86.2 \\
115.0 \\
44.8 \\
23.1 \\
92.5 \\
74.8 \\
1 . .1 \\
42.7 \\
45.2 \\
26.3 \\
59.6 \\
67.9 \\
45.5 \\
28.7 \\
44.9 \\
15.2\end{array}$ & $\begin{array}{l}2.188 \\
3.549 \\
2.307 \\
2.368 \\
1.986 \\
2.753 \\
2.411 \\
2.454 \\
2.269 \\
2.530 \\
1.572 \\
2.840 \\
1.503 \\
1.446 \\
1.685 \\
1.752 \\
1.340 \\
2.211 \\
1.296\end{array}$ & $\begin{array}{r}51.7 \\
75.7 \\
35.0 \\
114.3 \\
40.6 \\
109.9 \\
63.9 \\
275.7 \\
169.1 \\
149.0 \\
110.4 \\
102.3 \\
68.9 \\
119.1 \\
94.4 \\
68.7 \\
77.5 \\
56.5 \\
49.5\end{array}$ & $\begin{array}{l}1.829 \\
3.709 \\
2.008 \\
2.712 \\
2.449 \\
2.089 \\
1.929\end{array}$ & $\begin{array}{r}26.8 \\
83.6 \\
17.5 \\
145.4 \\
214.3 \\
59.2 \\
31.1\end{array}$ & $\begin{array}{l}1.529 \\
3.875 \\
1.748 \\
3.106 \\
3.019 \\
1.585 \\
1.543\end{array}$ & $\begin{array}{r}6.0 \\
91.8 \\
2.3 \\
181.1 \\
287.5 \\
20.8 \\
4.9\end{array}$ \\
\hline
\end{tabular}


TABLE 4. Froth flow regime total mass flow rates $(\mathrm{kg} / \mathrm{s})$ and percentage differences $(\%)$.

\begin{tabular}{|c|c|c|c|c|c|c|c|c|c|c|c|c|c|}
\hline $\begin{array}{l}\text { Test } \\
\text { no. }\end{array}$ & $\begin{array}{l}\text { Flow } \\
\text { dir. }\end{array}$ & $\begin{array}{c}\text { Spool } \\
\text { no. }\end{array}$ & $W$ & $M F$ & $\%$ & MFA & $\%$ & MFB & $\%$ & MFC & $\%$ & MFD & \% \\
\hline $\begin{array}{l}247 \\
248 \\
258 \\
259 \\
261 \\
284 \\
285 \\
290 \\
298 \\
299\end{array}$ & $\begin{array}{l}F \\
F \\
F \\
F \\
F \\
R \\
R \\
R \\
R \\
R\end{array}$ & $\begin{array}{l}4 \\
4 \\
4 \\
4 \\
4 \\
4 \\
4 \\
4 \\
4 \\
4\end{array}$ & $\begin{array}{r}0.374 \\
1.550 \\
0.371 \\
1.559 \\
1.592 \\
-0.374 \\
-1.625 \\
-1.564 \\
-0.385 \\
-1.520\end{array}$ & $\begin{array}{r}0.496 \\
1.884 \\
0.521 \\
1.627 \\
1.973 \\
-0.357 \\
-1.882 \\
-1.861 \\
-0.395 \\
-2.060\end{array}$ & $\begin{array}{r}32.5 \\
21.6 \\
40.5 \\
4.4 \\
23.9 \\
-4.5 \\
15.8 \\
19.0 \\
2.6 \\
35.5\end{array}$ & $\begin{array}{l}0.711 \\
1.899 \\
0.693 \\
1.692 \\
2.018 \\
0.928 \\
1.941 \\
1.933 \\
0.914 \\
2.106\end{array}$ & $\begin{array}{r}90.0 \\
22.5 \\
86.8 \\
8.6 \\
26.7 \\
148.1 \\
19.5 \\
23.6 \\
1.4 \\
38.6\end{array}$ & $\begin{array}{l}1.020 \\
1.285 \\
0.922 \\
1.102 \\
1.357 \\
2.461 \\
1.802 \\
1.737 \\
2.149 \\
1.793\end{array}$ & $\begin{array}{r}172.7 \\
-17.1 \\
148.4 \\
-29.3 \\
-14.7 \\
558.1 \\
10.9 \\
11.0 \\
458.1 \\
18.0\end{array}$ & & & & \\
\hline
\end{tabular}


TABLE 5. Wave flow regime total mass flow rates $(\mathrm{kg} / \mathrm{s})$ and percentage differences $(\%)$.

\begin{tabular}{|c|c|c|c|c|c|c|c|c|c|c|c|c|c|}
\hline $\begin{array}{l}\text { Test } \\
\text { no. }\end{array}$ & $\begin{array}{l}\text { Flow } \\
\text { dir. }\end{array}$ & $\begin{array}{c}\text { Spool } \\
\text { no. }\end{array}$ & $W$ & MF & $\%$ & MFA & $\%$ & MFB & $\%$ & MFC & $\%$ & MFD & $\%$ \\
\hline $\begin{array}{l}44 \\
60 \\
156 \\
177 \\
179 \\
188\end{array}$ & $\begin{array}{l}F \\
F \\
F \\
R \\
R \\
R\end{array}$ & $\begin{array}{l}1 \\
1 \\
3 \\
3 \\
3 \\
3\end{array}$ & $\begin{array}{r}0.202 \\
0.493 \\
0.954 \\
-0.379 \\
-0.947 \\
-0.642\end{array}$ & $\begin{array}{r}0.135 \\
0.617 \\
0.572 \\
-0.533 \\
-0.557 \\
-0.611\end{array}$ & $\begin{array}{r}-33.3 \\
25.3 \\
-40.1 \\
41.8 \\
-41.1 \\
-4.8\end{array}$ & $\begin{array}{l}0.354 \\
0.953 \\
1.815 \\
0.993 \\
1.188 \\
0.933\end{array}$ & $\begin{array}{r}75.3 \\
93.3 \\
90.3 \\
162.0 \\
25.5 \\
45.4\end{array}$ & $\begin{array}{l}0.937 \\
1.472 \\
2.76 \\
1.839 \\
2.552 \\
1.425\end{array}$ & $\begin{array}{l}363.7 \\
198.5 \\
189.4 \\
385.1 \\
169.5 \\
121.9\end{array}$ & $\begin{array}{l}0.867 \\
0.768 \\
1.815\end{array}$ & $\begin{array}{r}329.3 \\
55.7 \\
90.3\end{array}$ & $\begin{array}{l}0.803 \\
0.401 \\
1.194\end{array}$ & $\begin{array}{r}297.4 \\
-18.7 \\
25.2\end{array}$ \\
\hline
\end{tabular}


The amount of change in slip ratio between the drag screen and the turbine is not a known quantity; however, assumptions as to this value can be made and applied to the data to discern a possible empirical relationship.

The mass flow data for the prototype spool tests given in Ref. 1 have been analyzed with equation (20). Mass flow rates in the forward flow direction for the three spools are randomly larger or smaller than the reference values; for reverse flows the same situation exists.

Applying the slip correction, with various assumptions of change in slip ratio between the turbine and drag screen, did not result in increased accuracy. 


\section{REFERENCES}

1. W. Stein, Measurements, Error Analysis, and Calculations of Water and Steam Individuai Mass Flow Rates, Velocities, and Related Flow Parameters Obtained From Single-Phase and Two-Phase Prototype Tests of the PKL Instrumented Spool Pieces for the U. S. NRC-RSRS 3-D P rogram, Lawrence Livermore Laboratory, Livermore, CA, UCRL-52717 (1979).

2. J. B. Colson and J. V. Gilbert, JAERI Instrumented Spool Piece Performance in Two-Phase Flow, INEL, Idaho Falls, Idaho.

3. H. Estranda, Jr., and J. D. Sheppard, Some Aspects of Interpreting Two-Phase Flow Measurements in Instrumefited Piping Spool Pieces, Lawrence Livermore Laboratory, Livermore, CA, NUREG-0280 (1977). 